\title{
First-principles calculations for the mechanical properties of $\mathrm{Ti}-\mathrm{Nb}-\mathrm{B}_{2}$ solid solutions \\ N.R. Mediukh ${ }^{\mathrm{a}}$, P.E.A. Turchi ${ }^{\mathrm{b}}$, V.I. Ivashchenko ${ }^{\mathrm{a}}$, V.I. Shevchenko ${ }^{\mathrm{a}}$
}

\author{
${ }^{a}$ Institute of Problems of Material Science, National Academy of Science of Ukraine, \\ Krzhyzhanosky str. 3, 03142 Kyiv, Ukraine \\ ${ }^{\mathrm{b}}$ Lawrence Livermore National Laboratory (L-352), P.O. Box 808, Livermore, CA 94551, USA
}

\section{Abstract}

First-principles calculations based on density functional theory and ultra-soft pseudopotentials were carried out to investigate electronic, mechanical, and thermodynamic properties of $\mathrm{Ti}-\mathrm{Nb}-\mathrm{B}_{2}$ solid solutions. The mixing energy is found to be negative for all compositions indicating that formation of the solid solutions is energetically favorable. An analysis of the electronic structure shows that the $\mathrm{Ti}-\mathrm{Nb}$ interactions are responsible for the stabilization of the solid solutions. A non-monotonic change of the density of states at the Fermi level was revealed. Despite the fact that the bulk modulus of $\mathrm{TiB}_{2}$ is lower compared to that of $\mathrm{NbB}_{2}$, calculated elastic constants, hardness and ideal shear strength gradually decrease on going from $\mathrm{TiB}_{2}$ to $\mathrm{NbB}_{2}$. The correlation between these values and the mixing energy is not observed. The calculated phonon spectra and the thermodynamic characteristics indicate that the thermodynamical properties of the solid solutions will change gradually between $\mathrm{TiB}_{2}$ and $\mathrm{NbB}_{2}$. The results obtained are compared with available experimental data.

\section{Introduction}

Titanium diboride $\left(\mathrm{TiB}_{2}\right.$, space group $\mathrm{P} 6 / \mathrm{mmm}$ No. 191) is well known as a material with relatively high strength and durability. It is characterized by high melting point, hardness, chemical inertness and wear resistance [1-2]. This material is widely used in such areas as impact resistant armors, cutting tools, crucibles, and wear resistant coatings. Also, $\mathrm{TiB}_{2}$ cathodes are used for the electrochemical reduction of alumina to pure aluminum [3]. Niobium is regarded as an alloying addition to titanium-based materials for an enhancement of high-temperature oxidation resistance [4]. Isostructural hexagonal titanium and niobium diborides form continues solid solutions, assuming that $\mathrm{Ti}$ atoms were substituted by $\mathrm{Nb}$ atoms in the metal sublattice. This model reproduces the actual atomic configurations in Ti-Nb-B $\mathrm{B}_{2}$ phases $[5,6]$. However, despite the fact that each phase $\mathrm{TiB}_{2}$ and $\mathrm{NbB}_{2}$ is well studied, the investigation of their alloys is in an infant stage. We did not find any experimental information about the electronic and mechanical properties of these alloys. The formation of continuous Ti-Nb- $\mathrm{B}_{2}$ solid solutions was 
confirmed by first-principles calculations [7]. It was found that the mixing energy of the solid solutions reaches maximum negative values for equiatomic compositions [7]. (For simplicity, below we will use also the term "alloy", along with term "solid solution").

The goal of this work was to fill the gap in the study of the properties of Ti-Nb-B $\mathrm{B}_{2}$ solid solutions by using a first-principles approach. The motivation of the present investigation was also the fact that, in some solid solutions, such as $\mathrm{TiC}-\mathrm{TiN}$ and $\mathrm{ZrC}-\mathrm{ZrN}$, the elastic moduli as well as hardness reach maximum values in the middle of the concentration range [8-11]. It was shown that this strength enhancement had an electronic origin $[9,10]$. It is assumed that the same situation would take place for $\mathrm{Ti}-\mathrm{Nb}-\mathrm{B}_{2}$ solid solutions.

In this work we present the results of the first-principles investigations of Ti-Nb- $\mathrm{B}_{2}$ alloys. The calculated total energy, electronic and phonon densities of states, elastic constants, hardness, shear and tensile ideal strengths, thermodynamical values are analyzed as functions of compositions.

The paper is organized as follows. In Sec. 2, the details of first-principles calculations are presented and discussed. Sec. 3 contains the calculated characteristics and their discussion. Finally, in Sec. 4, the main conclusions were summarized.

\section{Computational aspects}

Titanium and niobium diborides have a layered hexagonal structure of the $\mathrm{AlB}_{2}$-type with the space group P6/mmm (No. 191; Pearson symbol: hP3; Strukturbericht designation: C32). In Fig. 1 we show the unit cell for $\mathrm{TiB}_{2}$. The boron atoms lie on the corners of the hexagons with the three nearest neighbor boron atoms in each plane. The Ti atoms have 12 nearest neighbor B atoms and eight next nearest neighbor Ti atoms (six are on the metal plane and two out of the metal plane) [1].

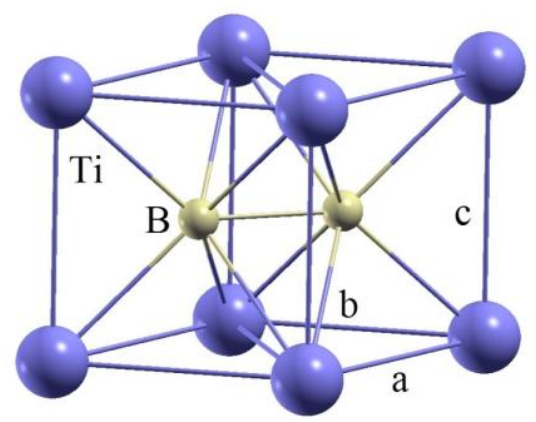

Fig. 1. Hexagonal unit cell for $\mathrm{TiB}_{2}$.

For the study of the pseudo-binary $\mathrm{Ti}_{1-\mathrm{x}} \mathrm{Nb}_{\mathrm{x}} \mathrm{B}_{2}$ alloys we considered the 24 -atom $(2 \times 2 \times 2)$ supercells constructed of the 3-atom hexagonal cells. The total number of different calculated configurations for $\mathrm{Ti}_{8-\mathrm{n}} \mathrm{Nb}_{\mathrm{n}} \mathrm{B}_{16}, \mathrm{n}=0-8$, structures were 22 . For each composition, we calculated 
all possible atomic configurations in the metal sublattice. As an example, three different atomic configurations in the metal sublattice for $\mathrm{Ti}_{2} \mathrm{Nb}_{6} \mathrm{~B}_{16}$ are shown on Fig. 2. Boron atoms are omitted in order to simplify the visual perception of the structure. Two titanium atoms located at (100) direction (a), (110) direction (b), (111) direction (c).

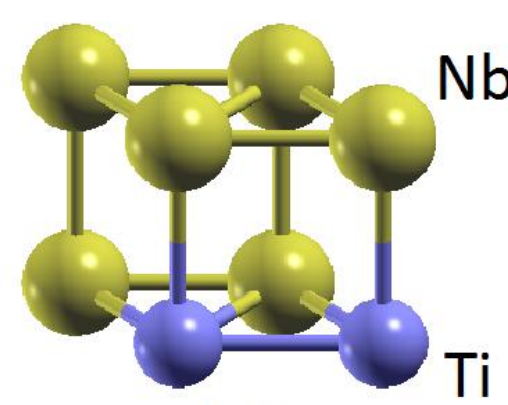

(a)

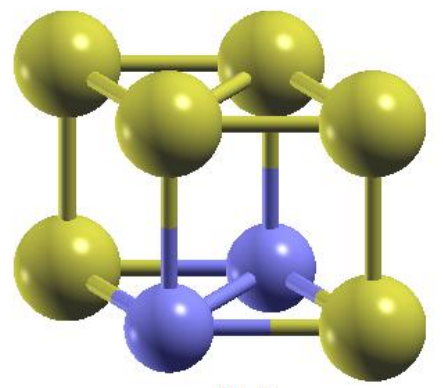

(b)

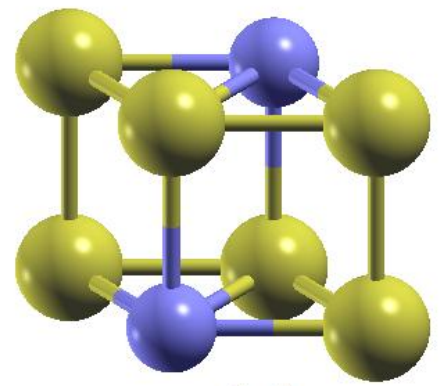

(c)

Fig. 2. Atomic configurations of the metal atoms in $\mathrm{Ti}_{2} \mathrm{Nb}_{6} \mathrm{~B}_{16}$. For simplicity, the boron atoms are not shown.

Scalar-relativistic band structure calculations within density functional theory (DFT) were carried out for supercells $\mathrm{Ti}_{8-n} \mathrm{Nb}_{n} \mathrm{~B}_{16}(\mathrm{n}=0-8)$ using the Quantum-ESPRESSO code [12]. We point out that we used the same supercells and input parameters for bulk $\mathrm{TiB}_{2}$, bulk $\mathrm{NbB}_{2}$ and solid solutions. The first-principles calculations were performed using periodic boundary conditions and the generalized gradient approximation (GGA) of Perdew, Burke and Ernzerhof (PBE) [13] for the exchange-correlation energy and potential. Vanderbilt ultra-soft pseudopotentials were used to describe the electron-ion interaction [14]. The criterion of convergence for the total energy was $10^{-4} \mathrm{Ry} /$ formula unit (i.e., $1.36 \cdot 10^{-3} \mathrm{eV} /$ formula unit). In order to speed up the convergence, each eigenvalue was convoluted by a Gaussian with a width $\sigma=0.03$ Ry $(0.408 \mathrm{eV})$. The integration in the Brillouin zone (BZ) was done on a set of special k-points determined according to the Monkhorst-Pack scheme [15] using a non-shifted mesh (4 4 4). The total number of k-points in the Brillouin zone was 64 . The cut-off energy of $36 \mathrm{Ry}(489.6 \mathrm{eV})$ was used. All initial structures were optimized by simultaneously relaxing the supercell basis vectors and the atomic positions inside the supercells using the Broyden-Fletcher-GoldfarbShanno (BFGS) algorithm [16]. The relaxation of the atomic coordinates and of the supercells was considered to be complete when atomic forces were less than $1.0 \mathrm{mRy} / \mathrm{Bohr}(25.7 \mathrm{meV} / \AA)$, stresses were smaller than $0.05 \mathrm{GPa}$, and the total energy during the structural optimization iterative process was changing by less than $0.1 \mathrm{mRy}(1.36 \mathrm{meV})$.

The phonon density of states (PHDOS) was calculated with the tetrahedron method implemented in the "Quantum-ESPRESSO" code using Density-Functional Perturbation Theory (DFPT) [17]. 
The elastic moduli of the solid solutions were investigated using the first-principles

In Fig. 3, the lattice parameters $\mathbf{a}$ and $\mathbf{c}$ of the alloys after structural optimization are presented as functions of composition. Despite the fact that the supercell volume is a linear function of composition (not shown here), both the parameters do not obey the Vegard law. One can see that $\mathbf{c}$ values are below the linear $\mathbf{c}(\mathrm{x})$ dependence, and $\mathbf{a}$ values are above the linear $\mathbf{a}(\mathrm{x})$ dependence, which means that the inter-atomic interaction in the c-direction is stronger than in the $\mathbf{a}$ - and $\mathbf{b}$-directions. Our calculations yielded lattice parameters of $\mathrm{a}=3.101 \AA, \mathrm{c}=3.338 \AA$ for $\mathrm{NbB}_{2}$ and $\mathrm{a}=3.024 \AA, \mathrm{c}=3.207 \AA$ for $\mathrm{TiB}_{2}$. These values are in good agreement with the available experimental values of $\mathrm{a}=3.107 \AA, \mathrm{c}=3.282 \AA$ for $\mathrm{NbB}_{2}[1]$ and $\mathrm{a}=3.030 \AA, \mathrm{c}=3.230 \AA$ for $\mathrm{TiB}_{2}$ [20] and with the results of previous calculations $\left(a=3.106 \AA, c=3.318 \AA\right.$ for $\mathrm{NbB}_{2}$ [21] and $\mathrm{a}=3.034 \AA$, $\mathrm{c}=3.226 \AA$ for $\mathrm{TiB}_{2}[22]$ )
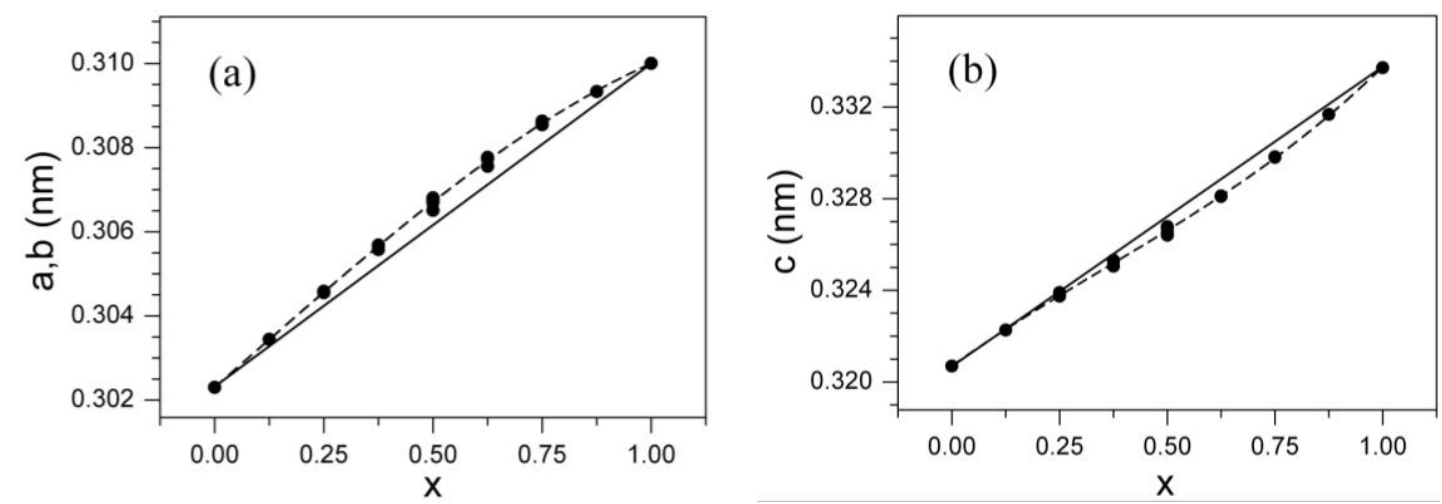
Fig. 3. Lattice parameters a, b (a) and c (b) for $\mathrm{Ti}_{1-\mathrm{x}} \mathrm{Nb}_{\mathrm{x}} \mathrm{B}_{2}$ alloys.

The stability of $\mathrm{Ti}_{1-\mathrm{x}} \mathrm{Nb}_{\mathrm{x}} \mathrm{B}_{2}$ alloys is determined by their Gibbs free energy of mixing at the temperature of zero Kelvin. Becouse the entropy and phonon contributions to the Gibbs free energy vanishe at $0 \mathrm{~K}$, the stability of the alloys can be derermined by the mixing energy:

$$
\mathrm{E}_{\text {mix }}(\mathrm{x})=\mathrm{E}_{\mathrm{T}}\left(\mathrm{Ti}_{1-\mathrm{x}} \mathrm{Nb}_{\mathrm{x}} \mathrm{B}_{2}\right)-\mathrm{x} \times \mathrm{E}_{\mathrm{T}}\left(\mathrm{NbB}_{2}\right)-(1-\mathrm{x}) \times \mathrm{E}_{\mathrm{T}}\left(\mathrm{TiB}_{2}\right),
$$

where $\mathrm{E}_{\mathrm{T}}$ are the total energies of the alloy, niobium and titanium diborides. The results of the calculations of the mixing energy presented in Figure 4 indicate that, in the entire concentration range, it is energetically favorable for $\mathrm{NbB}_{2}$ and $\mathrm{TiB}_{2}$ to mix and form the alloys, in agreement with experiment $[5,6]$. The polynomial fit to the calculated mixing energy pointsshows that the minimum of the $\mathrm{E}_{\text {mix }}(\mathrm{x})$ dependence falls on $\mathrm{x} \approx 0.43$.

To show the role of metal atoms for alloy stabilization, we performed the total-energy calculations of the alloys in which the boron cites were unfilled. The mixing energy of these hypothetical $\mathrm{Ti}_{1-\mathrm{x}} \mathrm{Nb}_{\mathrm{x}}$ alloys is presented in Fig. 4 as a function of composition. The mixing energy is negative for all compositions, which means that Ti-Nb interactions promote the strengthening of atomic cohesion. The minimum of the mixing energy falls on $\mathrm{x}=0.5$. The values of $\mathrm{E}_{\text {mix }}$ for both $\mathrm{Ti}_{1-\mathrm{x}} \mathrm{Nb}_{\mathrm{x}}$ and $\mathrm{Ti}_{1-\mathrm{x}} \mathrm{Nb}_{\mathrm{x}} \mathrm{B}_{2}$ alloys are comparable. It follows that the main contribution to the stabilization of the solid solutions comes from the direct $\mathrm{Ti}-\mathrm{Nb}$ interactions, while the Ti-B-Nb correlations shift the mixing energy minimum towards the compositions enriched by titanium.

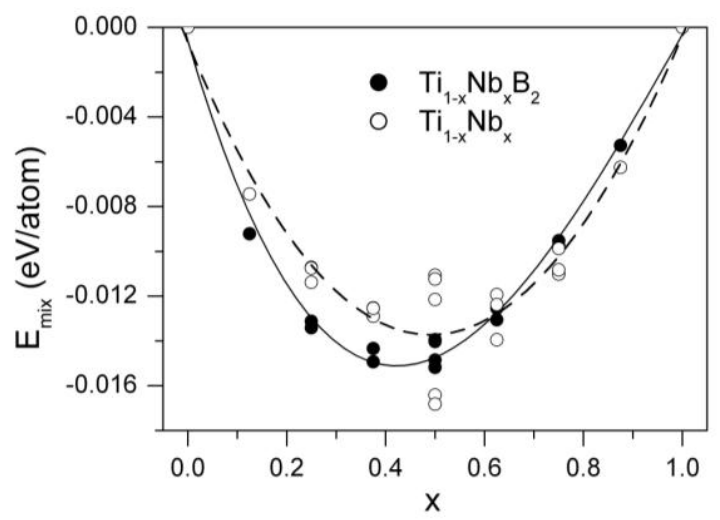

Fig. 4. Energy of mixing versus composition for $\mathrm{Ti}_{1-\mathrm{x}} \mathrm{Nb}_{\mathrm{x}} \mathrm{B}_{2}$ (solid circles and solid line) and hypothetical $\mathrm{Ti}_{1-\mathrm{x}} \mathrm{Nb}_{\mathrm{x}}$ (open circle and dashed line). The lines are the resulting polynomial fit to the calculated points.

We calculated the enthalpy of formation $\left(\mathrm{H}^{\mathrm{f}}\right)$ of the alloys allowing for the total energies of hexagonal Ti (space group $\mathrm{P}_{3} / \mathrm{mmc}$, No. 194), cubic Nb (space group Im-3m, No. 229) and rhombohedral $\alpha-B_{12}$ (space group R-3m, No. 166). The calculated enthalpy of formation for 
$\mathrm{TiB}_{2}$ and $\mathrm{NbB}_{2}$ are $-1.063 \mathrm{eV} /$ atom and $-0.718 \mathrm{eV} /$ atom, respectively. For the sake of comparison, the corresponding experimental values were $\mathrm{H}^{\mathrm{f}}=-1.137 \mathrm{eV}$ [23] and -1.087 eV/atom [24] for $\mathrm{TiB}_{2}$ and $\mathrm{H}^{\mathrm{f}}=-0.875 \mathrm{eV} /$ atom for $\mathrm{NbB}_{2}$ [23]. We see that our data agree rather well with these experimental results, as well as with the theoretical values of other authors $\mathrm{H}^{\mathrm{f}}=-$ $1.090 \mathrm{eV} /$ atom $\left(\mathrm{TiB}_{2}\right)$ and $-0.753 \mathrm{eV} /$ atom $\left(\mathrm{NbB}_{2}\right)$ [7]. Here, it should be noted that the calculated values of $\mathrm{H}^{\mathrm{f}}$ strongly depend on structural modifications of boron allowed for in the calculations [25]. For $\mathrm{TiB}_{2}$, the enthalpy of formation was found to change in the range of 1.078$1.175 \mathrm{eV} /$ atom depending on the structural characteristics of pure boron [25].

The calculated electronic densities of states (EDOSs) for $\mathrm{Ti}_{1-\mathrm{x}} \mathrm{Nb}_{\mathrm{x}} \mathrm{B}_{2}$ are presented in Fig. 5. The local EDOSs for $\mathrm{TiB}_{2}, \mathrm{NbB}_{2}$ and $\mathrm{Ti}_{0.5} \mathrm{Nb}_{0.5} \mathrm{~B}_{2}$ are shown in Fig. 6. The electronic spectra can be presented by four main bands that are marked as roman numerals. The band I consists of B 2s and metal d orbitals. Metal 3d and B 2p states form the band II below the Fermi level. The band III, just below the EDOS minimum is composed mostly by metal $3 \mathrm{~d}$ orbitals. Finally, the band IV that is located above $\mathrm{E}_{\mathrm{F}}$ consists mainly of metal $3 \mathrm{~d}$ states with a small admixture of B$2 \mathrm{p}$ states. This bond picture is consistent with that suggested in previous theoretical investigations [25,26]. On going from $\mathrm{TiB}_{2}$ to $\mathrm{NbB}_{2}$ the Fermi level shifts from the EDOS minimum deep into the metal band IV. In Fig. 7 we show the calculated EDOS at the Fermi level, $\mathrm{N}\left(\mathrm{E}_{\mathrm{F}}\right)$, as a function of composition. The value of $\mathrm{N}\left(\mathrm{E}_{\mathrm{F}}\right)$ for $\mathrm{TiB}_{2}$ is 0.13 states/(eV $\times$ unit cell), that is comparable with that gained from the measurement of electronic heat capacity - 0.46 states/(eV $\times$ unit cell) [27] and first-principles calculations - 0.44 states/(eV $\times$ unit cell) [25] and 0.16 states/(eV×unit cell) [27]. The substitution of $\mathrm{Ti}$ atoms by $\mathrm{Nb}$ atoms leads to a drastic increase in $\mathrm{N}\left(\mathrm{E}_{\mathrm{F}}\right)$. It is seen from Fig. 7 that the $\mathrm{N}\left(\mathrm{E}_{\mathrm{F}}, \mathrm{x}\right)$ dependence is not monotonic. The value of $\mathrm{N}\left(\mathrm{E}_{\mathrm{F}}\right)$ dramatically increases with $\mathrm{x}$ for $\mathrm{x} \leq 0.25$, then, in the range of $0.25-0.6$, it practically does not depend on $x$, and finally gradually increases with $x$ for $x>0.6$. Such a complex $N\left(E_{F}, x\right)$ dependence is caused by the specific shape of the EDOSs just above the Fermi level for $\mathrm{TiB}_{2}$ (cf. Fig. 5). We suppose that, for $\mathrm{Ti}_{1-\mathrm{x}} \mathrm{Nb}_{\mathrm{x}} \mathrm{B}_{2}$ alloys, the properties related to $\mathrm{N}\left(\mathrm{E}_{\mathrm{F}}\right)$ (electronic heat capacity, conductivity, superconductivity, and others) will also abnormally depend on composition. 


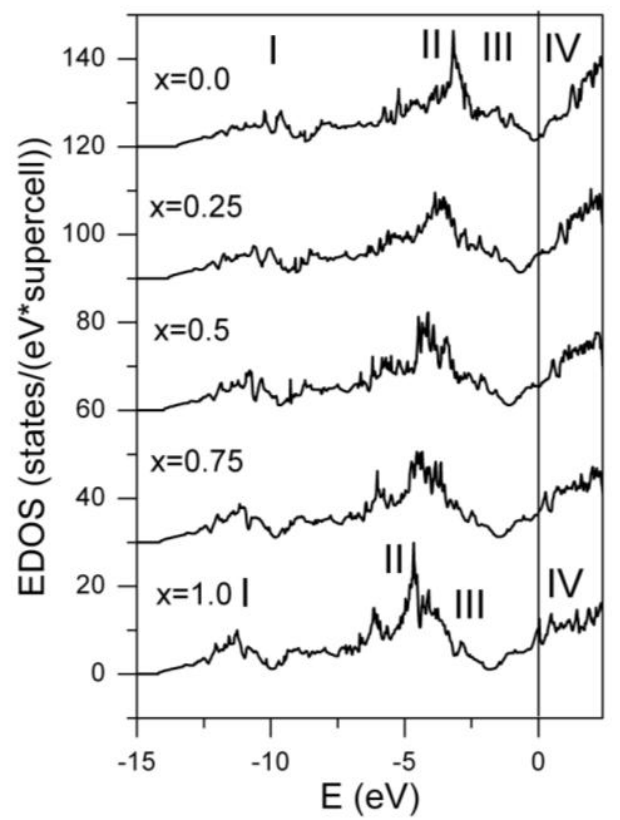

Fig. 5. Electronic density of states (EDOS) for $\mathrm{Nb}_{\mathrm{x}} \mathrm{Ti}_{1-\mathrm{x}} \mathrm{B}_{2}$ alloys (the24-atoms supercells). The vertical line locates the Fermi energy $\left(\mathrm{E}_{\mathrm{F}}\right)$.

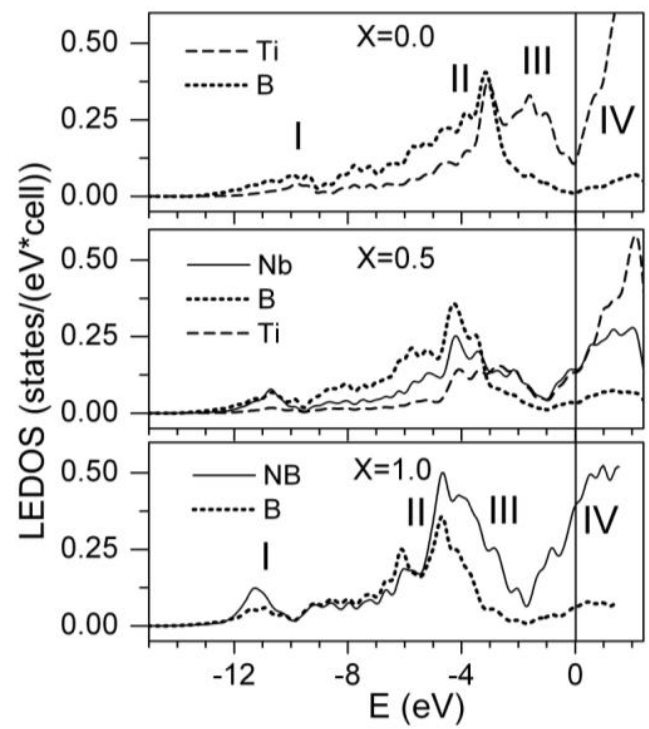

Fig. 6. Local electronic density of states (LEDOS) for $\mathrm{Nb}_{\mathrm{x}} \mathrm{Ti}_{1-\mathrm{x}} \mathrm{B}_{2}$ alloys (the 3-atoms cells). The vertical line locates the Fermi energy $\left(\mathrm{E}_{\mathrm{F}}\right)$.

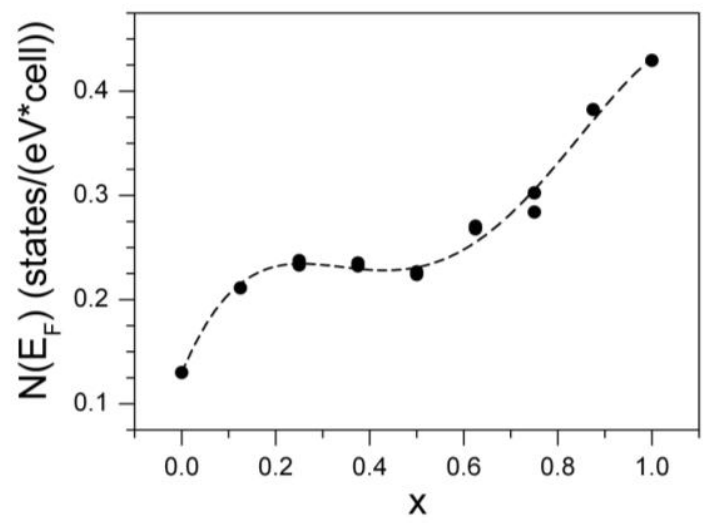


Fig. 7. Density of electronic states at the Fermi level, $N\left(E_{F}\right)$, for $\mathrm{Ti}_{1-\mathrm{x}} \mathrm{Nb}_{\mathrm{x}} \mathrm{B}_{2}$ alloys (the3-atoms cells) as a function of $\mathrm{x}$. The line is the resulting polynomial fitting to the calculated points.

We calculated the elastic moduli, and estimated the Vickers hardness of the alloys at equilibrium. The calculated Hill bulk (B), shear (G), Young's (E) modulus, bulk-to-shear modulus ratio $(\mathrm{B} / \mathrm{G})[28]$ and Vickers hardness $\left(\mathrm{H}_{\mathrm{V}}\right)$ for $\mathrm{TiB}_{2}$ and $\mathrm{NbB}_{2}$ are listed in Table 1 , and the concentration dependencies of these values for $\mathrm{Ti}_{1-\mathrm{x}} \mathrm{Nb}_{\mathrm{x}} \mathrm{B}_{2}$ are shown in Fig. 8 as functions of composition. One can see that the calculated moduli for $\mathrm{TiB}_{2}$ and $\mathrm{NbB}_{2}$ agree well with those obtained in other experimental and theoretical studies. For the alloys, we see that the calculated bulk modulus increases, and the values of $\mathrm{G}, \mathrm{E}$ and $\mathrm{H}_{\mathrm{V}}$ decrease gradually with increasing $\mathrm{x}$. An extreme behavior of these values with composition was not observed: the solid solutions have always lower values of the elastic constants and moduli than the composition weighted average values of $\mathrm{TiB}_{2}$ and $\mathrm{NbB}_{2}$, suggesting that the elastic properties are restricted by the individual components. It should be noted that the similar conclusion was previously obtained by Wang et al. for $\mathrm{TiN} / \mathrm{Si}_{\mathrm{x}} \mathrm{N}_{\mathrm{y}}$ superlattices [36].

Table 1. Calculated Hill bulk (B), shear (G), Young's (E) modulus, bulk-to-shear modulus ratio $(\mathrm{B} / \mathrm{G})$ and Vickers hardness $\left(\mathrm{H}_{\mathrm{V}}\right)$ for $\mathrm{TiB}_{2}$ and $\mathrm{NbB}_{2}$ in comparison with those obtain by other authors. The Vickers Hardness was estimated using the values of $\mathrm{E}$ [25]. For $\mathrm{TiB}_{2}$, the measured values of $\mathrm{H}_{\mathrm{V}}$ were 25-35 $\mathrm{GPa}$ [29].

\begin{tabular}{|c|c|c|c|c|c|c|}
\hline \multirow{4}{*}{ Phase } & $\begin{array}{c}\mathrm{B} \\
(\mathrm{GPa})\end{array}$ & $\begin{array}{c}\mathrm{G} \\
(\mathrm{GPa})\end{array}$ & $\begin{array}{c}\mathrm{E} \\
(\mathrm{GPa})\end{array}$ & $\mathrm{B} / \mathrm{G}$ & $\begin{array}{c}\mathrm{H}_{\mathrm{V}} \\
(\mathrm{GPa})\end{array}$ & Reference \\
\hline \multirow{5}{*}{$\mathrm{TiB}_{2}$} & 257 & 263 & 588 & 0.98 & 35.7 & Present \\
\cline { 2 - 7 } & 254.2 & 259.7 & 586.9 & 0.98 & 35.6 & DFT-LCAO[26] \\
\cline { 2 - 7 } & 253 & 268 & 594 & 0.94 & 36.0 & DFT-PBE [30] \\
\cline { 2 - 7 } & 254.7 & 263.7 & 582.2 & 0.97 & 35.3 & DFT-PBE [31] \\
\cline { 2 - 7 } & 247.5 & 264.3 & 584.7 & 0.94 & 35.5 & Experiment [33] \\
\cline { 2 - 7 } & 244 & 262 & 579 & 0.93 & 35.1 & Experiment [34] \\
\hline \multirow{3}{*}{$\mathrm{NbB}_{2}$} & 282 & 226 & 535 & 1.25 & 32.5 & Present \\
\cline { 2 - 7 } & 292 & 212 & 512 & 1.38 & 31.1 & DFT-PBE [35] \\
\hline
\end{tabular}

To evaluate the alloying effect on the ductility, the bulk-to-shear modulus ratio, B/G, as a function of concentration $\mathrm{x}$ are plotted in Fig. 8. The higher or lower the B/G ratio is the more ductile or brittle the material is, respectively [28]. The critical value that separates ductile and 
brittle materials is approximately 1.75 . Figure 8 shows that the $B / G$ ratio increases with $x$, however does not reach the critical value. Based on the trends for the $\mathrm{B} / \mathrm{G}$ ratio, one can conclude that the ductility of the alloys increases gradually as the $\mathrm{Nb}$ content increases.

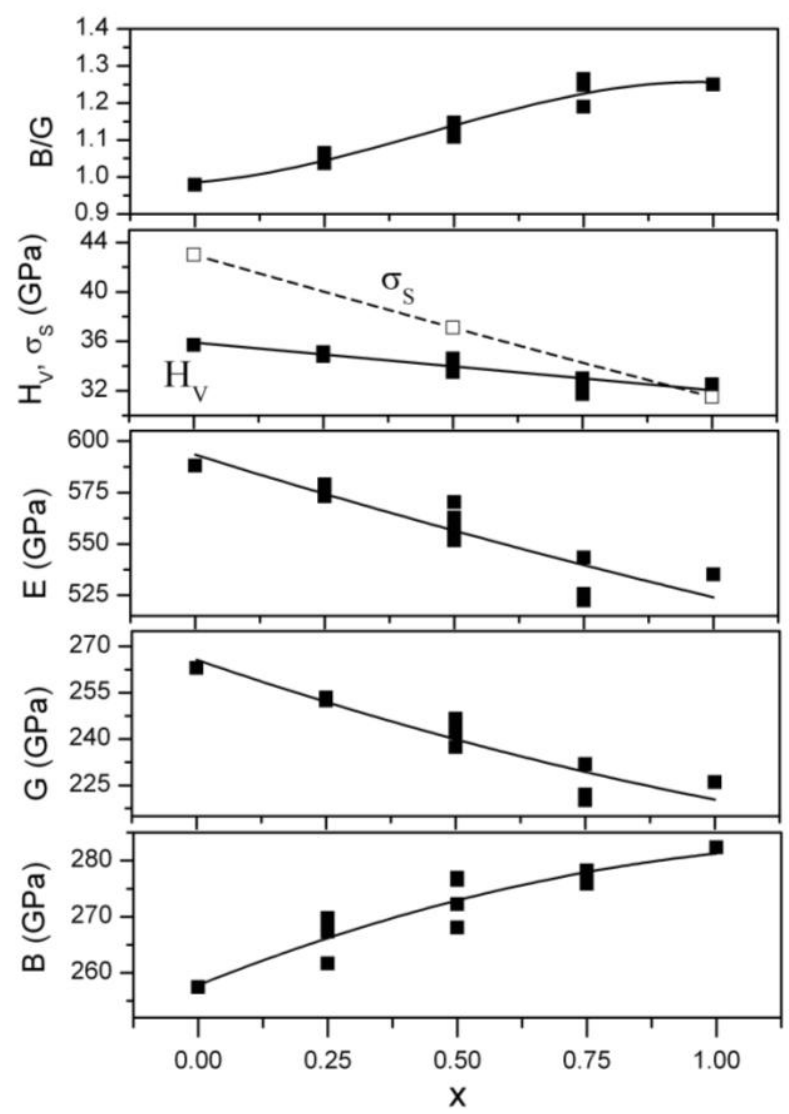

Fig. 8. Calculated bulk modulus (B), elastic constants $(\mathrm{G}, \mathrm{E})$, Vickers hardness $\left(\mathrm{H}_{\mathrm{V}}\right)$, ideal shear strength $\left(\sigma_{\mathrm{S}}\right)$, and $\mathrm{B} / \mathrm{G}$ ratio for $\mathrm{Ti}_{1-\mathrm{x}} \mathrm{Nb}_{\mathrm{x}} \mathrm{B}_{2}$ alloys as functions of concentration $\mathrm{x}$ (squares). The solid lines are the resulting cubic interpolation of the calculated points.

The tensile and shear stress-strain curves for some compositions of $\mathrm{Ti}_{1-\mathrm{x}} \mathrm{Nb}_{\mathrm{x}} \mathrm{B}_{2}$ alloys were calculated to investigate the behavior of the alloys under finite strains. The calculated tensile and shear stress-strain relations are shown in Fig. 9 ( $a$ and b, respectively). The calculated ideal tensile strengths for the alloys are lower than for $\mathrm{TiB}_{2}(62.0 \mathrm{GPa})$ and $\mathrm{NbB}_{2}(64.6 \mathrm{GPa})$. The shear ideal strengths for $\mathrm{Ti}_{1-\mathrm{x}} \mathrm{Nb}_{\mathrm{x}} \mathrm{B}_{2}$ were found to be $43.0 \mathrm{GPa}(\mathrm{x}=0.0), 37.1 \mathrm{GPa}(\mathrm{x}=0.5)$ and 31.5 GPa $(\mathrm{x}=1.0)$. Given this finding, one can suppose that the ideal shear strength of the pseudo-binary alloys will decreases gradually on going from $\mathrm{TiB}_{2}$ to $\mathrm{NbB}_{2}$. The calculated ideal shear strengths are comparable with the calculated Vickers hardness (cf. Figs. 8 and 9), which means that the approach for the estimate of the Vickers hardness from the elastic moduli for these alloys is quite justified. 

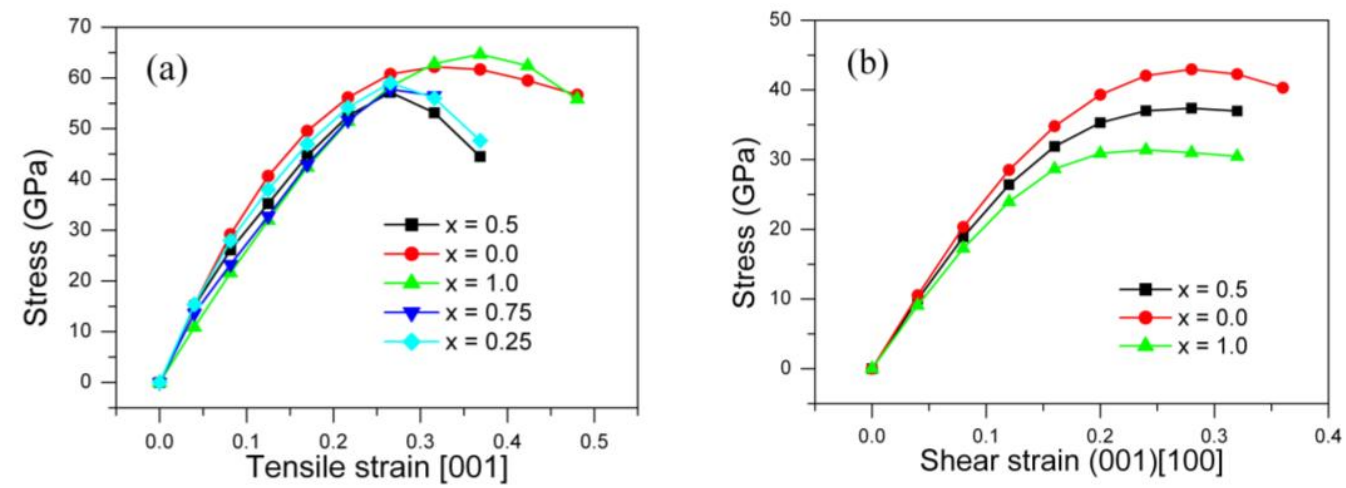

Fig. 9. Stress-strain relations of $\mathrm{Ti}_{1-\mathrm{x}} \mathrm{Nb}_{\mathrm{x}} \mathrm{B}_{2}$ for tensile (a) and shear strains (b).

The calculated phonon densities of states (PHDOS, $g(\omega)$ ) of $\mathrm{Ti}_{1-\mathrm{x}} \mathrm{Nb}_{\mathrm{x}} \mathrm{B}_{2}$ are shown in Fig. 10. We also calculated the composition weighted average PHDOSs of $\mathrm{TiB}_{2}$ and $\mathrm{NbB}_{2}$, i.e., $\mathrm{g}_{\mathrm{av}}=$ $(1-\mathrm{x}) \times \mathrm{g}_{\mathrm{TiB} 2}+\mathrm{x} \times \mathrm{g}_{\mathrm{NbB} 2}$ shown in Fig. 10 as dashed line. For $\mathrm{TiB}_{2}$, both the experimental and calculated PHDOSs agree rather well. There is the difference between $g_{\text {alloy }}(\omega)$ and $g_{a v}(\omega)$ for each composition of the alloys: $g_{a v}(\omega)$ shifts towards larger $\omega$. However, the larger the PHDOS at large frequencies is, the larger (more positive) contribution to the vibrational free energy becomes. It follows that lattice vibrations will promote the stabilization of $\mathrm{Ti}_{1-\mathrm{x}} \mathrm{Nb}_{\mathrm{x}} \mathrm{B}_{2}$ alloys at finite temperatures.

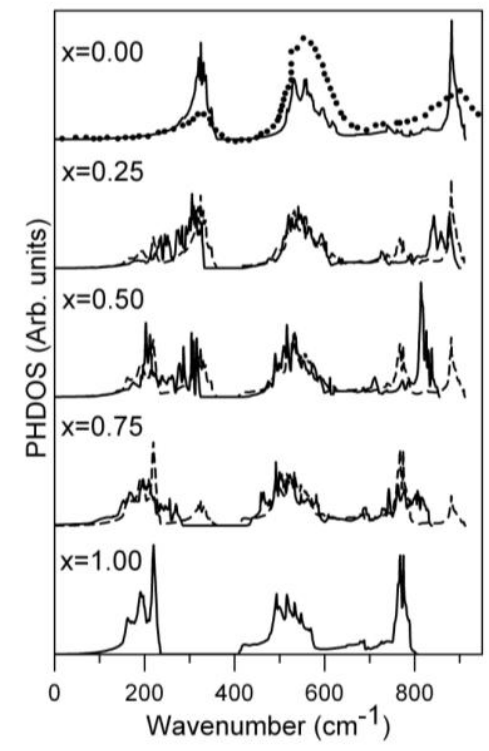

Fig. 10. Calculated phonon density of states (PHDOS) for $\mathrm{Ti}_{1-\mathrm{x}} \mathrm{Nb}_{\mathrm{x}} \mathrm{B}_{2}$ (solid line) and the composition weighted average PHDOSs of $\mathrm{TiB}_{2}$ and $\mathrm{NbB}_{2}$ (dashed line). For comparison, the experimental PHDOS measured by using the technique of inelastic neutron scattering for $\mathrm{TiB}_{2}$ is also presented (dotted line) [37].

Using the calculated PHDOSs, we investigated various thermodynamic characteristics: heat capacity $\left(\mathrm{C}_{\mathrm{v}}\right)$, phonon entropy $\left(\mathrm{S}_{\mathrm{p}}\right)$, phonon free energy $\left(\mathrm{F}_{\mathrm{p}}\right)$ and phonon energy $\left(\mathrm{E}_{\mathrm{p}}\right)$ as functions 
of temperature. The dependences of $\mathrm{C}_{\mathrm{v}}$ on temperature for $\mathrm{Ti}_{1-\mathrm{x}} \mathrm{Nb}_{\mathrm{x}} \mathrm{B}_{2}, \mathrm{x}=0,0.51$, are shown in Fig. 11. For all temperatures, the $\mathrm{C}_{\mathrm{v}}(\mathrm{T})$ curves for the alloys are arranged between the curves for $\mathrm{TiB}_{2}$ and $\mathrm{NbB}_{2}$. We found the similar temperature behavior of the other thermodynamical characteristics mentioned above (not shown here). The comparison of the calculated $\mathrm{C}_{\mathrm{v}}(\mathrm{T})$ curves with the experimental one for $\mathrm{TiB}_{2}$ was done in Fig. 12. We considered a low-temperature region, since, in our calculations, lattice anharmonicity was not taken into account. The calculated curve agrees well with the experiment one.

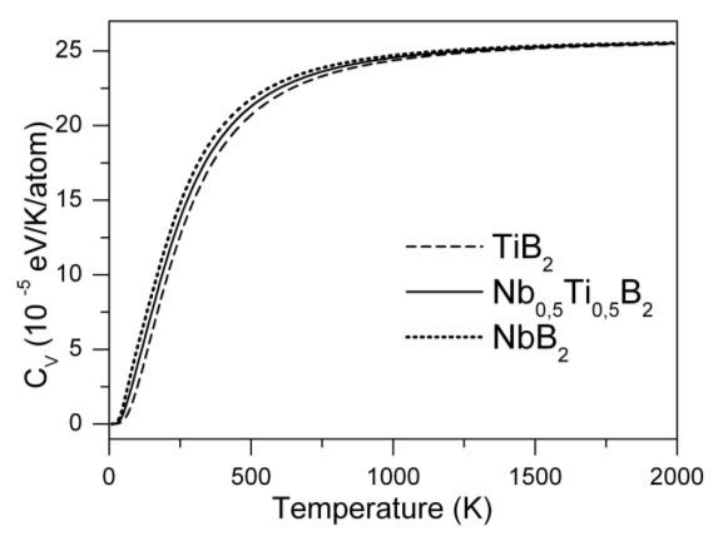

Fig. 11. Heat capacities $\left(C_{V}\right)$ as functions of temperatures for $\mathrm{TiB}_{2}, \mathrm{Ti}_{0.5} \mathrm{Nb}_{0.5} \mathrm{~B}_{2}$ and $\mathrm{NbB}_{2}$.

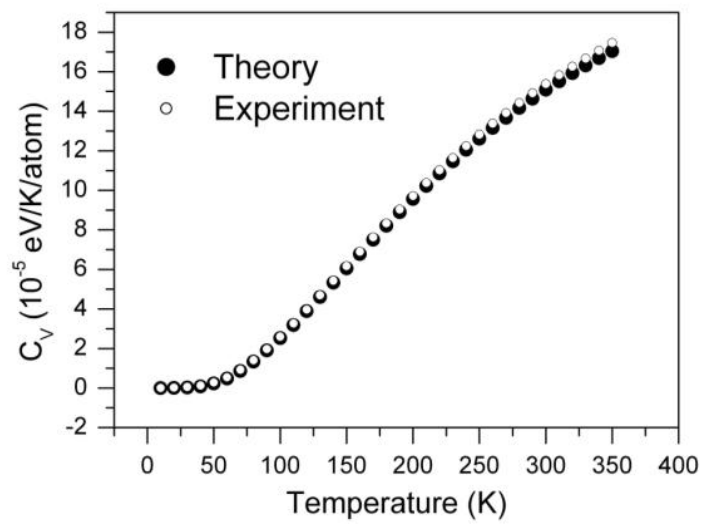

Fig. 12. Comparison of the calculated and experimental [38] $\mathrm{C}_{\mathrm{V}}$ curves for $\mathrm{TiB}_{2}$.

\section{Conclusions}

To investigate the electronic structure, elastic properties, stress-strain relations, and thermodynamical characteristics of $\mathrm{Ti}_{1-\mathrm{x}} \mathrm{Nb}_{\mathrm{x}} \mathrm{B}_{2}$ alloys, the DFT and ultra-soft pseudo-potentials have been used. The following main conclusions follow from this investigation:

1) The mixing energies of the pseudo-binary alloys were negative for all compositions indicating the possibility of the formation of a continuous series of solid solutions.

2) Deviation from Vegard's law for lattice parameters points to that the stabilization of the solid solutions occurs due to a strengthening of the interaction between the layers in $\mathrm{z}$ direction caused by $\mathrm{Ti}-\mathrm{Nb}$ interactions. 
3) The comprehensive analysis of the effect of composition on the density of electronic

states was performed. It was found that the dependence of the density of electronic states at the Fermi level was non-monotonic, which was due to the peculiarity of the density of electronic states for $\mathrm{TiB}_{2}$ just above the Fermi level.

4) It was shown that the shift of the densities of phonon states for the alloys towards low frequencies compared to the composition weighted average densities of phonon states for $\mathrm{TiB}_{2}$ and $\mathrm{NbB}_{2}$ will be mainly responsible for the stabilization of the pseudo-binary alloys at finite temperatures.

5) The tensile ideal strengths for the alloys are below those for $\mathrm{TiB}_{2}$ and $\mathrm{NbB}_{2}$.

6) The calculated elastic constant G, E, B/G ratio, Vickers hardness, and ideal shear strength gradually decrease on going from $\mathrm{TiB}_{2}$ to $\mathrm{NbB}_{2}$. The solid solutions have always lower values of the elastic constants and moduli than the composition weighted average values of $\mathrm{TiB}_{2}$ and $\mathrm{NbB}_{2}$, suggesting that the elastic properties are restricted by the individual components. The bulk modulus $\mathrm{B}$ increases with the $\mathrm{Nb}$ content.

7) The calculated characteristics agree rather well with available experimental and theoretical data of other authors.

Summarizing, against all expectations, we did not find any correlations of the calculated characteristics mentioned above with the mixing energy: they gradually change with composition without any extremums.

We hope that, results presented in this paper will provide useful guidance to researchers who are interested in the synthesis of superhard bulk materials and thin films based on transition metal borides.

\section{Acknowledgement}

This work was supported by the STCU contract No. 5964. The work of P. E. A. T. was performed under the auspices of the U. S. Department of Energy by the Lawrence Livermore National Laboratory under contract No. DE-AC52-07NA27344.

\section{References}

[1] V. I. Matkovich, G.V. Samsonov, P. Hagenmuller, and T. Lundstrom, Boron and Refractory Borides, Springer, Berlin, 1977.

[2] K. Upadhyay, J. M. Yang, and W. P. Hoffmann, Materials for Ultrahigh Temperature Structural Applications, Am. Ceram. Soc. Bull 76:51-56, 1997.

[3] Ronald G. Munro, Material Properties of Titanium Diboride, J. Res. Natl. Inst. Stand. Technol. 105:709-720, 2000. 
[4] S. Lampman, Wrought titanium and titanium alloys Metals Handbook, Tenth Edition, Vol. 2:592-633, 1990.

[5] G. V. Samsonov and V. S. Neshpor, Investigation of the mutual diffusion of titanium and niobium borides, Dokl. AN SSSR, 101(5):899-900, 1955.

[6] G. V. Samsonov and V. S. Neshpor, Research into the formation of isomorphous boride alloys, Zh. Fiz. Khim., 29(5):839-845, 1955.

[7] Yu Nakama1, H. Ohtani, and M. Hasebe, Thermodynamic Analysis of the Nb-Ti-B Ternary Phase Diagram, Materials Transactions, 50(5):984-993, 2009.

[8] V. Richter, A. Beger, J. Drobniewski, I. Endler, and E. Wolf, Characterisation and wear behaviour of TiN- and $\mathrm{TiC}_{x} \mathrm{~N}_{1-x}$-coated cermets, Mater. Sci. Eng. A209:353-357, 1996.

[9] V.I. Ivashchenko, P.E.A. Turchi, A. Gonis, L.A. Ivashchenko, and P.L. Scrynsckyy, Electronic origin of elastic properties of titanium carbonitride alloys, Metallurgical and Materials Transactions, 37A:3391-3396, 2006.

[10] V.I. Ivashchenko, P.E.A. Turchi and V.I. Shevchenko, First-principles study of elastic and stability properties of ZrC-ZrN and ZrC-TiC alloys, J. Phys.: Condens. Matter. 21:395503-8, 2009.

[11] R.W. Harrison and W.L. Lee, Processing and properties of $\mathrm{ZrC}, \mathrm{ZrN}$ and $\mathrm{ArCN}$ ceramics: a review, Advances in Applied Ceramics 115:294-307,2016.

[12] P. Giannozzi, S. Baroni, N. Bonini, M. Calandra, R. Car, C. Cavazzoni, D. Ceresoli, G.L. Chiarotti, M. Cococcioni, I. Dabo, A. Dal Corso, S. de Gironcoli, S. Fabris, G. Fratesi, R. Gebauer, U. Gerstmann, C. Gougoussis, A. Kokalj, M. Lazzeri, L. Martin-Samos, N. Marzari, F. Mauri, R. Mazzarello, S. Paolini, A. Pasquarello, L. Paulatto, C. Sbraccia, S. Scandolo, G. Sclauzero, A.P. Seitsonen, A. Smogunov, P. Umari, and R.M. Wentzcovitch, QUANTUM ESPRESSO: a modular and open-source software project for quantum simulations of materials, J. Phys.: Cond. Matter 21:395502-19, 2009.

[13] J.P. Perdew, K. Burke, and M. Ernzerhof, Generalized Gradient Approximation Made Simple, Phys. Rev. Lett. 77:3865-3868, 1996.

[14] D. Vanderbilt, Soft self-consistent pseudopotentials in a generalized eigenvalue formalism, Phys. Rev. B 41:7892-7895, 1990.

[15] H.J. Monkhorst, J.D. Pack, Special points for Brillouin-zone integrations, Phys. Rev. B 13:5188-5192, 1976.

[16] S.R. Billeter, A. Curioni, and W. Andreoni, Efficient linear scaling geometry optimization and transition-state search for direct wavefunction optimization schemes in density functional theory using a plane-wave basis, Comput. Mater. Sci. 27:437-445, 2003. 
[17] S. Baroni, S. De Gironcoli, A. Dal Corso, and P. Gianozzii, Phonons and related crystal properties from density-functional perturbation theory, Rev. Mod. Phys. 73:515-562, 2001.

[18] R. Golesorkhtabar, P. Pavone, J. Spitaler, P. Pusching, and C. Draxl, ElaStic: A tool for calculating second-order elastic constants from first-principles, Comput. Phys. Commun. 184:1861-1873, 2013.

[19] Xue Jiang, J. Zhao, and Xin Jiang, Correlation between hardness and elastic moduli of the covalent crystals, Comput. Mater. Sci. 50:2287-2290, 2011.

[20] B. Post, F. Wglaser, D Moskowitz, Transition metal diborides, J. Acta Metall, 2(1): 20-25, 1954.

[21] Shi-Yu Liu, Shiyang Liu, De-Jun Li, Hongli Dang, Yingdi Liu, Sha Xue, Wenhua Xue and Sanwu Wang, Bonding, stability, and electronic properties of the $\mathrm{BC}_{3}$ honeycomb monolayer structure on $\mathrm{NbB}_{2}(0001)$, Phys. Rev. B 88:115434-6, 2013.

[22] Yan Hai-yan, Wei Qun, Chang Shao-mei, Guo Ping, A first-principle calculation of structural, mechanical and electronic properties of titanium borides, Trans. Nonferrous Met. Soc. China 21:1627-1633, 2011.

[23] V. T. Witusiewicz, A. A. Bondar, U. Hecht, S. Rex, and T. Ya. Velikanova, The Al-B-NbTi system: I. Re-assessment of the constituent binary systems B-Nb and B-Ti on the basis of new experimental data, J. Alloy. Compd. 448:185-194, 2008.

[24] T.J. Yurick and K.E. Spear, Thermodynamics of $\mathrm{TiB}_{2}$ from Ti-B-N studies, Thermodynamics of Nuclear Materials, Vol. I:73-90, 1979.

[25] LI Yan-feng, XU Hui, XIA Qing-lin, and LIU Xiao-liang, First-principles calculation of structural and thermodynamic properties of titanium boride, J. Cent. South Univ. Technol. 18:1773-1779, 2011.

[26] R. Kumar, M.C. Mishra, B.K. Sharma, V. Sharma, J.E. Lowther, V. Vyas, and G. Sharma Electronic structure and elastic properties of $\mathrm{TiB}_{2}$ and $\mathrm{ZrB}_{2}$, Computational Materials Science 61:150-157, 2012.

[27] Tian De-cheng and Wang Xiao-bing, Electronic structure and equation of state of $\mathrm{TiB}_{2}$, Journal of Physics: Condensed Matter, 4:8765-8772, 1992.

[28] S.F. Pugh, Relations between the elastic moduli and the plastic properties of polycrystalline pure metals, Philos. Mag. 45:823-843, 1954

[29] B. Basu, G.B. Raju, and A.K. Suri, Processing and properties of monolithic $\mathrm{TiB}_{2}$ based materials, International Materials Reviews, 51:352-374, 2006.

[30] H.Y. Wang, F.Y. Xue, H. Zhao, and D.J. Li, First-Principles Calculation of Elastic Properties of $\mathrm{TiB}_{2}$ and $\mathrm{ZrB}_{2}$, Adv. Mat. Res. 150-151:40-43, 2011. 
[31] A. Waskowska, L. Gerward, J.S. Olsen, K.R. Babu, G. Vaitheeswaran, V. Kanchana, A. Svane, V.B. Filipov, G. Levchenko, and A. Lyaschenko, Thermoelastic properties of $\mathrm{ScB}_{2}, \mathrm{TiB}_{2}$, $\mathrm{YB}_{4}, \mathrm{HoB}_{4}$ : experimental and theoretical studies, Acta Mater. 59:4886-4894, 2011.

[32] Ronald G. Munro, Material Properties of Titanium Diboride, J. Res. Natl. Inst. Stand. Technol. 105:709-720, 2000.

[33] Hassel Ledbetter and Takaho Tanaka, Elastic-Stiffness Coefficients of Titanium Diboride, J. Res. Natl. Inst. Stand. Technol. 114:333-339, 2009.

[34] P. Spoor, J. Maynard, M. Pan, D. Green, J. Hellmann, and T. Tanaka, Elastic constants and crystal anisotropy of titanium diboride, Appl. Phys. Lett., 70:1959-1961, 1997.

[35] E. Regalado and R. Escamilla, Elastic properties of superconducting $\mathrm{NbB}_{2+\mathrm{x}}$ obtained from first-principles calculations, J. Phys.: Condens. Matter 19:376209-8, 2007.

[36] S. Wang, R. Gudipati, A.S. Rao, T.J. Bostelmann and Y.G. Shen, First-principles calculations for the elastic properties of nanostructured superhard TiN/Si $\mathrm{N}_{\mathrm{y}}$ superlattices, Appl. Phys. Lett. 91: 081916-3, 2007.

[37] R. Heid, B. Renker, H. Schober, P. Adelmann, D. Ernst, and K.-P. Bohnen, Lattice dynamics and electron-phonon coupling in transition-metal diborides, Phys. Rev. B 67:180510(R)-4, 2003.

[38] F. Edgar and Jr. Westrum, Hypostoichiometric titanium diboride $\left(\mathrm{TiB}_{1.984}\right)$ and hyperstoichiometric tantalum diboride $\left(\mathrm{TaB}_{2.11}\right)$ : the heat capacity and thermodynamic properties from 5 to 350 K, J. Chem. Thermodynamics 10:629-636, 1978. 